\title{
Genomic breeding values' prediction including populational selfing rate in an open-pollinated Eucalyptus globulus breeding population
}

\author{
Marianella Quezada ${ }^{1,2} \cdot$ Ignacio Aguilar $^{1} \cdot$ Gustavo Balmelli $^{3}$ (i)
}

Received: 14 May 2021 / Revised: 17 November 2021 / Accepted: 27 November 2021 / Published online: 7 February 2022 (C) The Author(s) 2022

\begin{abstract}
In forest tree breeding programs, open-pollinated families are frequently used to estimate genetic parameters and evaluate genetic merit of individuals. However, the presence of selfing events not documented in the pedigree affects the estimation of these parameters. In this study, 194 open-pollinated families of Eucalyptus globulus Labill. trees were used to compare the precision of estimated genetic parameters and accuracies of predicted breeding values with the conventional pedigreebased model (ABLUP) and the pedigree-genomic single-step model (ssGBLUP). The available genetic information for pairwise parent-offspring allows us to estimate an actual populational selfing rate of 5.4\%. For all the growth and disease resistance traits evaluated, the inclusion of selfing rate was effective in reducing the upward bias, between 7 and $30 \%$, in heritability estimates. The predictive abilities for ssGBLUP models were always higher than those for ABLUP models. In both cases, a considerable reduction of predictive abilities was observed when relatedness between training and validation populations was removed. We proposed a straightforward approach for the estimation of the actual selfing rate in a breeding population. The incorporation of this parameter allows for more reliable estimation of genetic parameters. Furthermore, our results proved that ssGBLUP was effective for the accurate estimation of genetic parameters and to improve the prediction of breeding values in presence of selfing events, thus a valuable tool for genomic evaluations in Eucalyptus breeding programs.
\end{abstract}

Keywords Eucalyptus $\cdot$ Disease resistance $\cdot$ Selfing rate $\cdot$ Single-step genomic evaluation

\section{Introduction}

In breeding programs, genetic improvement depends on a reliable estimation of genetic parameters as heritability, genetic correlations and breeding values. Conventional tree breeding programs use phenotype information provided by

Communicated by: F. Isik

Gustavo Balmelli

gbalmelli@inia.org.uy

1 Instituto Nacional de Investigación Agropecuaria (INIA). Programa Nacional de Investigación en Producción de Leche, Estación Experimental "Wilson Ferreira Aldunate", Ruta 48 $\mathrm{km}$ 10, Canelones, Uruguay

2 Departamento de Biología Vegetal, Facultad de Agronomía-Universidad de la República, Av Gral Eugenio Garzón 780, Montevideo, Uruguay

3 Instituto Nacional de Investigación Agropecuaria (INIA). Programa Nacional de Investigación en Producción Forestal, Estación Experimental del Norte, Ruta 5 km 386, Tacuarembó, Uruguay progeny testing, together with pedigree records to obtain estimations of these parameters. Open-pollination is one of the most frequently used mating designs, since its simplicity and low cost allow to evaluate the genetic merit of a large number of trees. Thus, genetic parameters are estimated by applying a model that assumes a complete outcrossing mating, where open-pollinated families are represented as half-sibs. However, the presence of offspring from parents related to each other or with both parents in common (full siblings) establishes new types of relationships that are not considered by the pedigree in open-pollinated families (Namkoong 1965). In addition, selfing is frequent in Eucalyptus species and, since it is not documented in the pedigree, it affects the estimation of genetic parameters and breeding values, and therefore the selection of superior trees (Squillace 1974; Bush et al. 2011). The errors of relatedness among and within families, generated by pedigree mistakes or simply by having incomplete pedigrees, as well as the presence of selfings, can be corrected using genomic information (Muñoz et al. 2014; Mphahlele et al. 2020).

Eucalyptus species show predominantly outcrossing mating systems though there is also a considerable degree 
of self-fertilization, with selfing rates ranging between 0.04 and 0.55 (Eldridge et al. 1993). For Eucalyptus globulus Labill., a mean selfing rate of 0.40 has been reported, with a range of 0.05 to 0.87 , associated with individual tree variation and flowering density (Patterson et al. 2004). Ignoring the mixed-mating system, with both selfing and outcrossing, is one of major sources of error in the estimation of genetic parameters, inflating genetic variances estimates, and consequently the heritability (Eldridge et al. 1993). To consider the existence of self-fertilization in open-pollinated populations, in estimating the heritability in Eucalyptus, a kinship coefficient greater than $1 / 4$ is generally used, typically $1 / 3$ or $1 / 2.5$ (Squillace 1974). Although the proposed adjustment is based on a rate of selfing of $30 \%$, in most populations the actual value is unknown (Volker et al. 1990). In addition, this correction only avoids the overestimation of the additive variance and heritability, but has no impact on individual breeding values.

Currently the animal model, referred to as an individual tree mixed model when applied in forest tree breeding, is the approach generally used for the estimation of genetic parameters and the prediction of breeding values (Balmelli et al. 2013; Cappa et al. 2016). The main advantage of this model is the simultaneous estimation of breeding values for parents and progeny. In this approach, an average numerator relationship matrix $(\boldsymbol{A})$ is used to indicate the additive covariance between all individuals, taking values of 0.5 between parent-offspring and 0.25 for half-sibs of an open-pollinated population. This matrix also allows the easy incorporation of higher levels of relatedness based on pedigree information. Dutkowski et al. (2001) developed an adjustment to include the selfing effect in this matrix, resulting in an increased level of relatedness in the population. Simulation studies that incorporated this $\boldsymbol{A}$ modified matrix with the specific populational selfing rate in the individual tree model approach resulted in less biased estimates of variance components and breeding values (Dutkowski et al. 2001). However, the application and further evaluation of this methodology on real breeding populations are limited by the lack of knowledge of the selfing rate.

The development of high-throughput genotyping technologies has provided genetic information distributed throughout the genome. The availability of genome-wide molecular markers for several forest tree species, such as Eucalyptus, Pinus, and Populus, enables to predict genomic breeding value to implement new breeding strategies, such as genomic selection (Meuwissen et al. 2001). The Genomic Best Linear Unbiased Prediction (GBLUP) includes a genomic relationship matrix $(\boldsymbol{G})$ derived from markers in a mixed model approach for estimation of genomic breeding values (VanRaden 2008). This matrix accurately estimates the genetic similarity, enabling to account for the actual proportion of genome share among individuals and the variation due to Mendelian segregation (Visscher et al. 2006). The application of GBLUP can be a notably valuable tool in forest tree breeding programs to overcome one of its main challenges, the detection of unknown relationships, so improving the accuracy of genetic parameters and breeding values estimation and, therefore, increasing the selection efficiency (Tan et al. 2017; Ukrainetz and Mansfield 2020).

Nowadays, the genomic selection approach has been expanded to include pedigree and genomic information in a single unified model, which has been proposed by Aguilar et al. (2010), Christensen and Lund (2010), and Legarra et al. (2009), and is known as single-step evaluation. Since one of the problems faced by forest tree breeding programs is the high cost of genotyping, this method allows the phenotypic and pedigree data of the entire breeding program to be incorporated in the same analysis with the genotypic information of a subset of the population. Different methods to calculate the genomic relationships have been tested to improve the adjustment of this matrix to the pedigree-based relationship matrix and compared the accuracies of predictions (Forni et al. 2011; Vitezica et al. 2011). However, for species with mixed-mating systems as Eucalyptus, the average numerator relationship matrix can be affected by shallow pedigree structures, due to, for example, cryptic relatedness and presence of selfings. Thus, modifications of the pedigree-based relationship matrix to complete pedigree information and integrate selfing rate, as well as the effects on accuracy of breeding values predicted by single-step evaluations, remain to be assessed.

Therefore, using data from a breeding population of $E$. globulus, the objectives of this study were (a) to compare the precision of breeding values predicted with the conventional pedigree-based model and with the pedigree-genomic single-step model and (b) to estimate the population's selfing rate and test the predictive ability of both approaches when the selfing rate is incorporated into the analysis.

\section{Materials and methods}

\section{Breeding population and phenotyping}

The E. globulus population belongs to the breeding program of the Instituto Nacional de Investigación Agropecuaria (INIA) of Uruguay. The population comprises two generations of breeding. The first generation includes materials from Australia and Chile, and selections from Uruguayan commercial plantations. The second generation was formed 
by the recombination of the first-generation individuals by open-pollination. A progeny test with 194 families from both generations was installed in Lavalleja (latitude $34^{\circ} 110$ $\mathrm{S}$; longitude $54^{\circ} 540 \mathrm{~W}$; altitude $206 \mathrm{~m}$ ) following a randomized complete block design, with three replicates and eight-tree row plots, with a total of 4,601 plants.

In the first year, a gradual increase of defoliation was detected in the trial, caused by a severe infection of Teratosphaeria nubilosa (Cooke) Crous \& U.Braun. Therefore, traits associated with growth and response to infection were evaluated. To measure the susceptibility to disease, the degree of defoliation (DEF) was assessed on the whole crown. In this species, the adult foliage is less susceptible to $T$. nubilosa than juvenile foliage (Milgate et al. 2005; Balmelli et al. 2013). Thus, the precocity of vegetative phase change, which may represent a means of escape from infection, was assessed as the fraction of the canopy exhibiting adult foliage (ADFO). Both diseaserelated traits were evaluated using a visual scale with classes of $10 \%$ at 21 months. The growth traits total height (HT) and diameter at breast height $(\mathrm{DBH})$ were measured at 26 months and at 50 months, respectively. A total of 3,853 individuals presented high-quality phenotypic records in the data set and have been used for the analysis. For a more detailed description of the progeny trial and phenotypic data, see Balmelli et al. (2016).

\section{Genotyping}

A subset of 1,008 randomly selected individuals, representing 179 families with 4-8 individuals per family, were genotyped using the Illumina Infinium EUChip60K SNP chip (Silva-Junior et al. 2015) at GeneSeek Inc. (Lincoln, NE, USA). The SNP calling was performed using the Maidenaria section reference. The marker data was filtered to select markers with call rate $>0.90$ and a minor allele frequency $(\mathrm{MAF})>0.05$, and individuals with call rate $>0.80$ using QCF90 software (Masuda et al. 2019). As a result, 16,364 SNPs were selected for analysis from 975 samples. The registration errors in the pedigree were corrected based on SNP information, following the approach of Muñoz et al. (2014). In order to estimate the selfing rate in this population, the 78 parents still standing were also genotyped. The same genotype platform and filtering criteria were used for these individuals. Pairwise linkage disequilibrium (LD) was estimated between SNPs based on the squared correlation coefficient $\left(r^{2}\right)$ for SNPs located on the same chromosome. The LD decay was fitted by a nonlinear regression model between adjacent sites using the $\mathrm{R}$ script by Marroni et al. (2011).

\section{Selfing rate estimation}

The population's selfing rate was calculated as the proportion of offspring that resulted from self-fertilization based on the estimation of pairwise relatedness between parent-offspring. This analysis was carried out with a subset of 505 individuals, represented by 78 mothers and their offspring (427 individuals), with a mean of 5.5 trees per family (range 3-8). A subset of 1,152 SNP markers with a call rate $>0.90$, MAF $>0.05$ and in Hardy-Weinberg equilibrium assessed with a chi-squared test ( $p$-value $>0.05$ ) were used to selfing estimation.

Since the performance of algorithms to estimate relatedness varies depending on population composition, the likelihood estimators that allow for inbreeding, Milligan (M) (Milligan 2003) and Wang (W) (Wang 2007), were applied and compared. The use of simulated data is recommended to compare the performance of different estimators, as well as determine the bias and precision (Wang 2011). Thus, simulated marker data were generated to emulate the characteristics of the expected data (relationship types), using the allelic frequency distribution of the empirical markers. The bias and precision were estimated as the root mean square relative error (RMSE) and subsequently applied as an appropriate correction for the relatedness estimators of the real data. The simulated data were generated with the FAM-SIM code (https://github.com/ timothyfrasier/C_software), and the relatedness coefficients estimated using the RELATED R package (Pew et al. 2015).

The relatedness coefficients estimated for the parentoffspring pairs of the subset of 505 genotyped trees (78 mothers and 427 progeny) were compared with the expected relationship coefficient. Based on the empirical distribution, a threshold was defined by a parent-offspring relationship coefficient larger than one standard deviation from the mean. This threshold was chosen to declare each pair of trees as parent-outbreed or parent-self offspring. This also corresponds to the lack of overlap between distributions for the two new relationships defined (parent-outbreed and parent-self offspring). The corrected pedigree was improved by relabeling the selfed individuals with information from the male parents, and this improved pedigree was used in the subsequent analyzes.

To check the identity of the individuals relabeled as selfed, the inbreeding coefficients were estimated using a genomic relationship matrix $(\boldsymbol{G})$ for this subset of 505 genotyped trees (VanRaden 2008). The diagonal elements of the matrix $\boldsymbol{G}$ are $1+F$, where $F$ is the inbreeding coefficient. For outcrossed individuals, $F$ will be 0 and the diagonal elements of the matrix $\boldsymbol{G}$ will be 1, while 
for selfed or consanguineous individuals $F$ will be greater than 0 and the diagonal elements will be greater than 1 . Therefore, the average inbreeding in the population will be the average of the diagonal elements of the matrix $\boldsymbol{G}$ minus 1. Three alternative methods of construction of the realized relationship matrix were assessed following VanRaden (2008) and Forni et al. (2011): $\boldsymbol{G} \boldsymbol{O} \boldsymbol{F}$, where the $\boldsymbol{G}$ matrix is scaled to be analogous for the numerator relationship matrix; $\boldsymbol{G} \boldsymbol{D}$, weighting markers by reciprocal of their expected variance, and Greg, regressed the genomic relationships on the relationship matrix based on pedigree. These matrices were constructed with the subset of 1,152 SNPs and with the complete set of markers $(16,364)$.

\section{Statistical analysis}

\section{Numerator relationship matrix}

The average numerator relationship matrix $\boldsymbol{A}$ was computed from the improved pedigree data that included relabeled self-individuals. Additionally, following the methods described by Dutkowski et al. (2001), a modified numerator relationship matrix $(\boldsymbol{A s})$ was estimated to take into account the selfing rate in the population. Both matrices were created in the ASREML-R version 4.0 (Butler et al. 2018; R Core Team 2018) using the AINVERSE command, with the argument SELFING incorporating the selfing rate previously estimated from the genotyped parent-offspring subset of trees in the $\boldsymbol{A s}$ matrix.

\section{Pedigree-based model}

The following linear mixed model was applied for the pedigree-based model (ABLUP) to estimated breeding values for each trait:

$y=X \beta+Z_{p} p+Z_{a} a+\varepsilon$

where $\boldsymbol{y}$ is the vector of phenotypic observations, $\boldsymbol{\beta}$ is the vector of fixed effects, such as the overall mean and block, $\boldsymbol{p}$ is the vector of random plot effects, $\boldsymbol{a}$ is the vector of random effects of individual trees (i.e., breeding values), and $\boldsymbol{\varepsilon}$ is the vector of random residuals. The incidence $\boldsymbol{X}$ matrix relates the observations to the fixed effects, and $Z_{p}$ and $Z_{a}$ are the corresponding incidence matrices related to random effects $\boldsymbol{p}$ and $\boldsymbol{a}$. The vectors of plot and residual effects follow a $\operatorname{var}(\boldsymbol{p}) \sim N\left(0, \boldsymbol{I} \sigma_{p}^{2}\right)$ and $\operatorname{var}(\boldsymbol{\varepsilon}) \sim N\left(0, \boldsymbol{I} \sigma_{\varepsilon}^{2}\right)$ respectively, where $\boldsymbol{I}$ is the identity matrix, $\sigma_{p}^{2}$ the plot variance and $\sigma_{\varepsilon}^{2}$ the residual variance. In the pedigree-based approach the vector $\boldsymbol{a}$ was assumed to follow a $\operatorname{var}(\boldsymbol{a}) \sim N\left(0, \boldsymbol{A} \sigma_{a}^{2}\right)$ where $\boldsymbol{A}$ is the average numerator relationship matrix and $\sigma_{a}^{2}$ is the additive genetic variance. In order to investigate the effect of the selfing rate on the estimation of breeding values, a conventional $\boldsymbol{A}$ matrix has been used (ABLUP_S0), in addition to the $\boldsymbol{A s}$ which considers the estimated selfing rate for the population (ABLUP_S05).

\section{Single-step pedigree-genomic-based model}

In the single-step genomic blup method (ssGBLUP), both pedigree-based relationship and genomic-based relationship were incorporated into a single relationship matrix $(\boldsymbol{H})$ (Aguilar et al. 2010). The same linear model as for the pedigree-based method was used, but the $\boldsymbol{A}$ matrix was substituted by the $\boldsymbol{H}$ matrix.

First, the genomic relationship matrix was constructed following VanRaden (2008):

$$
G=\frac{Z Z^{\prime}}{2 \sum p_{j}\left(1-p_{j}\right)}
$$

where $Z$ is an $n \times m$ matrix of centered genotype scores ( $n=975$ is the number of genotyped individuals and $m=16,364$ is the number of markers), and $p_{j}$ is the reference allele frequency of the $j^{\text {th }}$ marker.

A critical step in the single-step evaluation is the adjustment of the genomic-based relationship matrix to be compatible with the pedigree-based relationship, to avoid a lack of convergence, large reranking or biases in the analyses (Misztal et al. 2013). For this reason, the $\boldsymbol{G}$ matrix was scaled so that the average of its diagonal elements and the average of the off-diagonal elements equal their corresponding averages on the pedigree-based relationship matrix only for the genotyped individuals ( $\boldsymbol{A}_{22}$ matrix) (Christensen 2012).

As the matrix $\boldsymbol{G}$ is not positive definite, to avoid potential problems with its inversion, it was weighted as proposed by Aguilar et al. (2010) with the scaled parameter $\alpha=0.95$ as

$G=\alpha G+(1-\alpha) A_{22}$

The inverse of the relationship matrix that combines pedigree and genomic information $\left(\boldsymbol{H}^{-1}\right)$ was derived by Aguilar et al. (2010) as

$H^{-1}=A^{-1}+\left[\begin{array}{cc}0 & 0 \\ 0 & G^{-1}-A_{22}^{-1}\end{array}\right]$

where $\boldsymbol{A}^{\mathbf{- 1}}$ is the inverse of the pedigree-based relationship matrix $\boldsymbol{A}$, and $\boldsymbol{G}^{-1}$ and $\boldsymbol{A}_{\mathbf{2 2}}^{-1}$ are the inverse of the genomic and pedigree relationship matrices for the genotyped individuals, respectively.

Two alternative pedigree-based matrices were used for the construction of the matrix $\boldsymbol{H}$ : (i) a conventional $\boldsymbol{A}^{\mathbf{- 1}}$ and $\boldsymbol{A}_{\mathbf{2 2}}^{\mathbf{- 1}}$ matrix (ssGBLUP_S0) and (ii) an $\boldsymbol{A s}\left(\boldsymbol{A s} \boldsymbol{s}^{-\mathbf{1}}\right.$ and $\boldsymbol{A} \boldsymbol{s}_{\mathbf{2 2}}^{-\mathbf{1}}$ ) matrix modified including the populational selfing rate (ssGBLUP_S05). 
The $\boldsymbol{G}$ and $\boldsymbol{H}$ matrices were calculated using the PREGSF90 software (Aguilar et al. 2011). The four models: ABLUP_S0, ABLUP_S05, ssGBLUP_S0 and ssGBLUP_S05 were analyzed in BLUPF90 software (Misztal et al. 2002).

\section{Model evaluation}

\section{Heritability and model-based accuracy}

The narrow sense heritability for all traits was estimated as follows:

$h^{2}=\frac{\sigma_{a}^{2}}{\sigma_{a}^{2}+\sigma_{p}^{2}+\sigma_{\varepsilon}^{2}}$

where $\sigma_{a}^{2}$ is the additive genetic variance, $\sigma_{p}^{2}$ is the plot variance, and $\sigma_{\varepsilon}^{2}$ is the residual variance.

The model-based accuracy $(r)$ of the predicted breeding values was estimated across the four models as follows:

$r=\sqrt{1-\frac{P E V}{\left(1+F_{i}\right) \sigma_{a}^{2}}}$

where PEV (prediction error variance) for the $i^{\text {th }}$ tree is the diagonal element of the inverse of the coefficient matrix of mixed model equations, and the diagonal elements of $\boldsymbol{A}$ or $\boldsymbol{H}$ contain the inbreeding coefficient of the $i^{\text {th }}$ individual as $1+F_{i}$, depending on ABLUP or ssGBLUP (Mrode 2014).

The Akaike Information Criteria (AIC) (Akaike 1974) was used to compare the fit of models and the significance of the selfing rate when this information is included in the model. Additionally, to compare whether the individual tree ranks differed among the models, the Spearman rank correlation was estimated. The proportion of common candidates in the top ranked 10\% (385 trees) was compared among the four different models.

\section{Cross-validation models}

The predictive performance of each model was evaluated through a 10-fold cross-validation approach. Since the training population is structured as half-sib families with different levels of relationship between them, as openpollinated families sharing common grandparents, two different strategies were employed to split the data into training and validation sets. For the first method (CVrandom), the data set was randomly split in ten nonoverlapping subsets, each containing equal number of genotyped and non-genotyped individuals. In the second strategy (CV-family), the ability to accurately predict breeding values based on genomic information of other family or distant relationship pedigree (e.g., grandparent level) was assessed. Thus, the whole family was sampled, so ten subsets approximately of the same size were created, each containing all individuals (genotyped and non-genotyped) of between 18 and 20 families. For both approaches, one subset was used as a validation population while the remaining subsets were used to predict the ledout individuals in the first population. This process is then repeated 10 times with each subset used exactly once as the validation data set. The above analysis was repeated 100 times, including new randomly assigned splits of individuals (CV-random) or families (CV-family).

The predictive ability can be estimated as the correlation between the predicted and the "true" breeding values. Since these values are unknown, the breeding values estimated with the pedigree, phenotypic and genomic information of all available trees were considered as the best estimates of "true" breeding values and used as reference. The Pearson correlation between the predicted breeding values only of genotyped individuals in validation data sets and the reference breeding values were calculated. Predictive ability was estimated as the mean correlation values of all validation data sets.

The prediction bias was calculated as the regression coefficient between the reference breeding values and those predicted with the different models (Isik et al. 2017). A regression coefficient of 1 indicates no bias, whereas values greater than one indicate deflation and values smaller than one indicate inflated predictions. The Spearman rank correlation was also calculated between the reference and predicted breeding values to determine if the ranking differed among approaches.

\section{Results}

\section{Selfing estimation}

The simulation study showed very consistent performance for $\mathrm{M}$ and $\mathrm{W}$ likelihood estimators, with positive small bias in both pairwise relatedness for the parent-offspring relationship class $(0.011$ and 0.010 for $\mathrm{M}$ and $\mathrm{W}$ estimators, respectively). This result allows us to evaluate the resolution expected and correct the estimated pairwise relatedness of the empirical data. Since highly similar results and a high correlation were found between the $\mathrm{M}$ and $\mathrm{W}$ likelihood estimators in the E. globulus real data, only results for the $\mathrm{W}$ estimator are shown. The distribution of the parentoffspring pairwise relationship is expected to be normal, centered at 0.5 . Nevertheless, the 427 pairwise relationships evaluated presented a bimodal normal distribution. The primary peak occurs at the expected value (0.5) and a second, much smaller peak occurs around 0.8 (Fig. 1). From the observed distribution and using a threshold defined by empirical data, 23 pairwise relationships were 


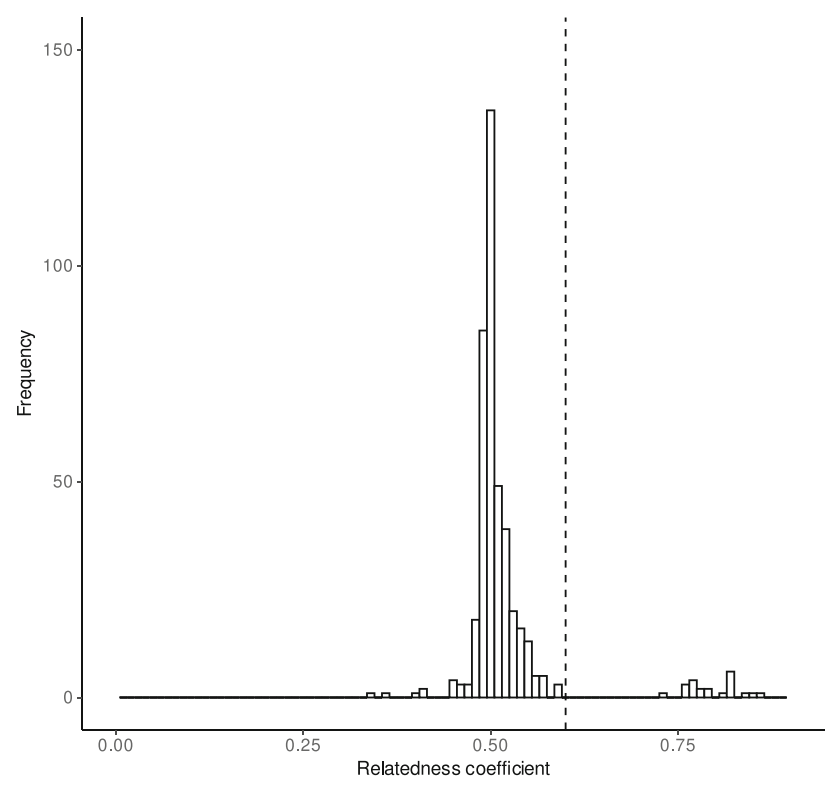

Fig. 1 Distribution of pairwise relatedness coefficients for parentoffspring using likelihood estimator (expected value $=0.5$ ). The vertical dashed line corresponds to the threshold used to identify selfed individuals in the population

declared inconsistent; thus, 23 individuals were identified as selfed progeny (5.4\% of the sample) and reassigned in the improved pedigree with complete parent information. These self-individuals presented above 0.7 and up to 0.9 pairwise relationships coefficients, well above those expected for a parent-offspring.

Genomic relationship matrices, computed following three alternative methods, confirmed the pairwise relationship classification obtained from the likelihood estimators. The genomic matrices computed using the subset and the complete set of markers were comparable, with correlations between them of $0.92,0.92$, and 0.86 , for $\boldsymbol{G} \boldsymbol{O} \boldsymbol{F}$, $\boldsymbol{G D}$ and $\boldsymbol{G r e g}$ matrices, respectively. The estimated average inbreeding was remarkably high for selfed progeny $(0.25)$, whereas the outbred progeny showed an observed value of -0.02 , close to the expected value $(0.0)$ derived from the diagonal of the $\boldsymbol{G} \boldsymbol{O} \boldsymbol{F}$ matrix computed with the subset of 1,152 markers. The same pattern was observed for the $\boldsymbol{G D}$ and $\boldsymbol{G r e g}$ matrices, with an average of 0.23 and 0.30 for selfed progeny and -0.01 and 0.0 for outbred progeny. Although a lower inbreeding was observed with the complete set of markers for the selfed progeny, the differences were consistent between both groups of individuals for the $\boldsymbol{G} \boldsymbol{O} \boldsymbol{F}$ matrix $(0.09$ and -0.14 for selfed and outbred progeny). Moreover, this difference was maintained in $\boldsymbol{G D}$ and $\boldsymbol{G r} \boldsymbol{e g}$ matrices, where the average inbreeding was 0.13 and 0.21 for selfed individuals, and -0.10 and -0.07 for outbred progeny, respectively. When the covariance of the parent-offspring was evaluated, clear differences were observed between the two new parent-offspring relationship declared. The mean parent-offspring covariance for parentoutbred offspring was $0.48,0.49$ and 0.49 for the $\boldsymbol{G} \boldsymbol{O} \boldsymbol{F}$, $\boldsymbol{G D}$ and $\boldsymbol{G r e g}$ matrices, close to the expected value of 0.5 . Likewise, mean values of $0.87,0.85$ and 0.91 were derived from the $\boldsymbol{G O F}, \boldsymbol{G D}$ and $\boldsymbol{G r e g}$ matrices for the new category of parent-self offspring (expected value 1.0). Similar results were observed for the complete set of markers.

\section{Genetic relationship matrices}

Both pedigree data and marker information were used to estimate relationship between individuals in the progeny trial of open-pollinated families. The numerator relationship matrix ( $\boldsymbol{A}$ and $\boldsymbol{A}_{22}$ ) was very sparse, with discrete class between individuals with coefficients ranging from 0 to 1.5 (unrelated to identity self offspring). As expected, the relationship coefficient between individuals for each discrete class increased with the incorporation of the population selfing rate ( $\boldsymbol{A} \boldsymbol{s}$ and $\boldsymbol{A} \boldsymbol{s}_{\mathbf{2} 2}$ ). Conversely, the realized relationship matrix based on genomic information presented a continuous distribution with values between -0.128 and 1.477 (Table 1). Thus, the use of marker information allowed to estimate the proportion of genome shared by different individuals, capturing the specific level of relatedness between individuals and relationships not registered by pedigree.

The mean values within the different relationship groups tended to be higher for pedigree matrices with and without incorporation of populational selfing rate for genotyped progeny $\left(\boldsymbol{A}_{22}\right.$ and $\left.\boldsymbol{A s}_{22}\right)$, compared to the $\boldsymbol{G}$ matrix (Table 1). Particularly, higher mean values were obtained when the populational selfing rate was incorporated. Despite this apparent overestimation of relatedness, the incorporation of selfing rate in the numerator relationship matrix resulted in a slight increase in the correlation between this matrix and the $\boldsymbol{G}$ matrix (0.765), compared with the matrix that did not take into account the population's selfing rate $(0.756)$.

\section{Model comparison}

The heritability estimates obtained with the genomic model (ssGBLUP_S0) were lower than with the pedigreedbased model (ABLUP_S0) for disease resistance traits, and equal or moderately higher for growth traits (Table 2). The heritability varied from 0.33 to 0.66 in ABLUP_S0 and from 0.29 to 0.62 in the ssGBLUP_S0 approach. The incorporation of the population selfing rate yielded a marginal reduction in the pedigreed based model (ABLUP_S0 vs ABLUP_S05) and in the genomic model (ssGBLUP_S0 vs ssGBLUP_S05). In addition, the AIC values showed that the genomic information improved the goodness-of-fit compared with the based-pedigree models 
Table 1 Mean (and standard deviation) of the estimated pairwise relatedness coefficients for each relationship class for three relationships matrices: $\boldsymbol{A}_{\mathbf{2 2}}$ average numerator relationship matrix for genotyped individuals; $\boldsymbol{A} \boldsymbol{s}_{22}$ average numerator relationship matrix for genotyped individuals including $5 \%$ populational selfing rate and $\boldsymbol{G}$ : genomic-based relationship matrix

\begin{tabular}{|c|c|c|c|}
\hline Relationship class & $A_{22}$ & $A s_{22}$ & $G$ \\
\hline \multicolumn{4}{|l|}{ Identity } \\
\hline Outbred offspring & 1.000 (NA) & 1.030 (NA) & $0.875(0.118)$ \\
\hline Selfed offspring & 1.500 (NA) & 1.510 (NA) & $1.090(0.093)$ \\
\hline \multicolumn{4}{|l|}{ First-degree } \\
\hline Outbred half-sibs & 0.250 (NA) & 0.283 (NA) & $0.276(0.130)$ \\
\hline Selfed-outbred sibs & 0.500 (NA) & 0.538 (NA) & $0.406(0.096)$ \\
\hline Selfed-selfed sibs & 1.000 (NA) & 1.030 (NA) & $0.756(0.069)$ \\
\hline \multicolumn{4}{|l|}{ Second-degree } \\
\hline Half uncle-nephew & 0.125 (NA) & 0.148 (NA) & $0.095(0.061)$ \\
\hline Half uncle-nephew (one selfed ${ }^{\mathrm{a}}$ ) & 0.250 (NA) & 0.282 (NA) & $0.204(0.047)$ \\
\hline \multicolumn{4}{|l|}{ Third-degree } \\
\hline Half first cousin & 0.062 (NA) & 0.072 (NA) & $0.077(0.073)$ \\
\hline Half first cousin (one selfed ${ }^{\mathrm{a}}$ ) & $0.125(\mathrm{NA})$ & 0.146 (NA) & $0.116(0.056)$ \\
\hline \multicolumn{4}{|l|}{ Forth-degree } \\
\hline Half first cousin once removed & 0.031 (NA) & 0.040 (NA) & $0.033(0.037)$ \\
\hline Half first cousin once removed (one selfed ${ }^{\mathrm{a}}$ ) & 0.062 (NA) & 0.076 (NA) & $0.038(0.029)$ \\
\hline \multicolumn{4}{|l|}{ Fith-degree } \\
\hline Second cousin & 0.016 (NA) & 0.021 (NA) & $0.030(0.048)$ \\
\hline Unrelated & 0 (NA) & 0 (NA) & $-0.003(0.060)$ \\
\hline
\end{tabular}

$N A$, not applicable

${ }^{\mathrm{a}}$ One individual relabeled as self for all traits (Table 3). For traits associated with the response to infection, the best fit was reached with the model that also consider populational selfing rate (ssGBLUP_S05), whereas for growth traits, the lowest AIC values correspond to genomic model in absence of selfing rate (ssGBLUP_S0).

Model-based accuracies of the predicted breeding values were evaluated for three classes of individuals: maternal parents, non-genotyped and genotyped offspring (Fig. 2). Accuracies for breeding values of maternal parents were quite similar for the four models evaluated, with averages across traits of 0.663 (ABLUP_S0), 0.678 (ABLUP_S05), 0.698 (ssGBLUP_S0) and 0.708 (ssGBLUP_S05). The inclusion of genomic information slightly increases the theoretical accuracy of the maternal and progeny breeding values, with the exception of disease-related traits in non-genotyped offspring. The incorporation of population selfing rate, both in the pedigree and genomic models (ABLUP_S0 vs ABLUP_S05 and ssGBLUP_S0 vs ssGBLUP_S05), did not generate a significant improvement in progeny accuracy either. For the genomic approaches, the mean of genotyped progeny accuracies for all traits (0.768 and 0.769 , for ssGBLUP_S0 and ssGBLUP_S05) were higher than non-genotyped progeny $(0.670$ and 0.675 , for ssGBLUP_S0 and ssGBLUP_S05), as was expected.
The proportion of common progeny candidates in the top 10\% (385 trees) ranking was used as a measure of the impact to include genomic information and selfing rate in the breeding values estimation (Table 4). The proportion of common candidates between ABLUP and ssGBLUP ranged from 76.3 to $89.3 \%$ when the populational selfing rate was not included in the models, and from 75.0 to $90.1 \%$ when it was included. These values indicate that there will be some changes in the ranking of individuals when genomic information is included, regardless of the incorporation of selfing rate. When the impact of populational selfing was evaluated, the proportion of common candidates varied for the different traits from 95.3 to $98.6 \%$ for ABLUP_S0 and ABLUP_S05, and from 97.3 to $99.1 \%$ for ssGBLUP_S0 and ssGBLUP_S05. These higher values indicate that selfing rate has low impact in the ranking of selections.

\section{Cross-validation}

The predictive ability of ABLUP_S0 ranged from 0.497 to 0.614 and from 0.098 to 0.272 in the $\mathrm{CV}$-random and CV-family cross-validation methods, respectively (Fig. 3). In comparison, the predictive ability for the ssGBLUP_S0 model ranged from 0.680 to 0.842 in the $\mathrm{CV}$-random 
Table 2 Heritability (and standard deviation) for models ABLUP_S0 (pedigree-based); ABLUP_S05 (pedigree rescaled to selfing rate in the population); ssGBLUP_S0 (combined pedigree marker-based) and
ssGBLUP_S05 (combined pedigree marker-based rescaled to selfing rate in the population)

\begin{tabular}{lllll}
\hline Trait_age (months) & ABLUP_S0 & ABLUP_S05 & ssGBLUP_S0 & ssGBLUP_S05 \\
\hline DEF_21 & $0.33(0.06)$ & $0.32(0.05)$ & $0.29(0.04)$ & $0.29(0.04)$ \\
ADFO_21 & $0.66(0.04)$ & $0.65(0.04)$ & $0.62(0.04)$ & $0.62(0.04)$ \\
HT_26 & $0.41(0.06)$ & $0.40(0.06)$ & $0.44(0.05)$ & $0.43(0.05)$ \\
DBH_50 & $0.50(0.07)$ & $0.46(0.07)$ & $0.51(0.05)$ & $0.50(0.05)$ \\
\hline
\end{tabular}

$D E F$, degree of defoliation; $A D F O$, fraction of adult folage in canopy; $H T$, total tree height; $D B H$, diameter at breast height

and from 0.546 to 0.720 in the $\mathrm{CV}$-family approach. The predictive abilities of the pedigree-genomic-based models (ssGBLUP) were always higher than those of the pedigree-based (ABLUP) models in both $\mathrm{CV}$ methods. Thus, the predictive abilities decreased $30 \%$ in the CVrandom method for all traits when comparing ssGBLUP vs ABLUP models. However, the reduction was especially strong, $60 \%$ for resistance traits and $80 \%$ for growth traits, when the relatedness between training and validation populations was intentionally removed (CV-family). This was expected, considering that for growth traits predictive abilities around 0.1 were found in the CV-family method. When we assessed the pairwise LD in this population, the LD decayed to an $r^{2}$ of 0.2 within $21.8 \mathrm{~kb}$ (Supplementary Fig. 1). Thus, some LD between markers and QTLs could be driving the predictions. The models that included the selfing rate had predictive abilities very similar to those of the homologous models with conventional $\boldsymbol{A}$ matrix (ABLUP_S0 vs ABLUP_S05 and ssGBLUP_S0 vs ssGBLUP_S05).

The degree of bias of the breeding values was low, with the pedigree-genomic-based methods showing lower bias (i.e., regression coefficients closer to one) compared to those of pedigree-based methods. Greater biases were observed for the CV-family cross-validation compared to the randomized cross-validation, with deflated predictions for disease resistance traits and inflated for growth traits
(Fig. 4). The inclusion of populational selfing rate in the models had almost no effect on bias. The Spearman rank correlations were close to the predictive ability and followed the same trend. Thus, the models with higher predictive abilities also presented higher rank correlation values. The inclusion of the selfing rate in the models also had no effect in the Spearman rank correlations (Fig. 5).

\section{Discussion}

\section{Populational selfing rate}

Molecular tools have been proven to be useful to study the mixed-mating system in Eucalyptus species (Tambarussi et al. 2018). Currently, the estimation of the outcrossing rate is mainly based on kinship allocation or sibling reconstruction methodologies (Kalinowski et al. 2007; Wang et al. 2012). Because these strategies were developed to work with a limited number of multiallelic markers, they are methodologically complex and computationally demanding, so it is difficult to use them efficiently in large SNP data sets. However, as we demonstrated in this study, comparing the expected and empirical distributions of relationship estimators for parent-offspring provides a straightforward procedure to identify progeny derived from selfing events. Although this strategy can only
Table 3 Akaike information criteria (AIC) for models ABLUP_S0 (pedigree-based); ABLUP_S05 (pedigree rescaled to selfing rate in the population); ssGBLUP_S0 (combined pedigree marker-based) and
ssGBLUP_S05 (combined pedigree marker-based rescaled to selfing rate in the population)

\begin{tabular}{lllll}
\hline Trait_age (months) & ABLUP_S0 & ABLUP_S05 & ssGBLUP_S0 & ssGBLUP_S05 \\
\hline DEF_21 & 27571 & 27570 & 27510 & $\mathbf{2 7 5 0 8}$ \\
ADFO_21 & 31461 & 31455 & 31251 & $\mathbf{3 1 2 4 1}$ \\
HT_26 & 42604 & 42604 & $\mathbf{4 2 5 6 0}$ & 42562 \\
DBH_50 & 16910 & 16911 & $\mathbf{1 6 8 4 1}$ & 16841
\end{tabular}

$D E F$, degree of defoliation; $A D F O$, fraction of adult folage in canopy; $H T$, total tree height; $D B H$, diameter at breast height

The model with the lowest AIC value for each trait is indicated in bold 


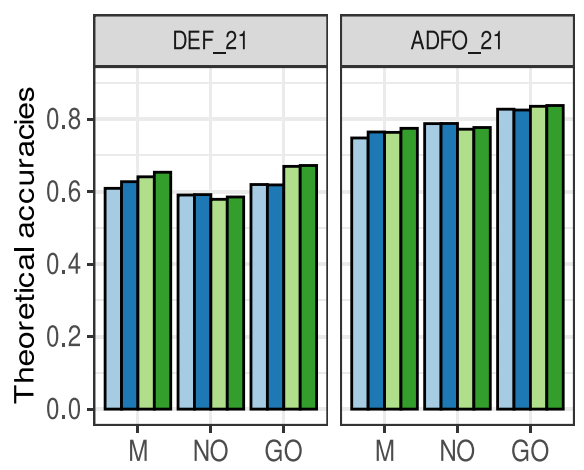

Fig. 2 Mean theoretical accuracies of breeding values for three classes of individuals: maternal parent (M), non-genotyped offspring (NO) and genotyped offspring (GO) for models fit using pedigree-based (ABLUP_SO), pedigree-based incorporating selfing rate in population

be implemented when a set of parental individuals are genotyped, the clear bimodal distribution for the parentoffspring relationships enabled to unequivocally identify individuals derived from self-fertilization (Fig. 1).

The precision of the pairwise relatedness estimates, as well as correct assignment of individuals to their relatedness category, mainly depends on the number and informativeness of molecular markers and the sample size. Simulations under different mating systems scenarios showed that a number of 800 SNPs are enough to obtain a rate of $95 \%$ of correct assignment (Kopps et al. 2015). Cappa et al. (2016) showed that 181 SNP markers allowed the estimation of the actual relatedness among 166 individuals from an open-pollinated progeny of $E$. grandis. Similarly, Klápště et al. (2017) employed a subset of 500 SNP markers for sibship reconstruction of 691 trees from an open-pollinated family of E. nitens. In our study, the number of neutral markers (1,152 SNPs) and the population size (427 parent-offspring pairwise comparisons) are higher than those used in other studies in forest tree species.

For open-pollinated progenies of Eucalyptus species, it is traditionally considered that up to $20-30 \%$ of individuals are selfed (Griffin and Cotterill 1988; Volker et al.

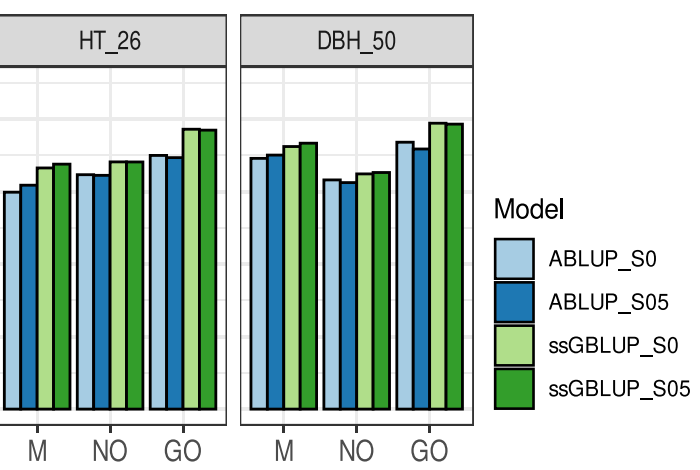

(ABLUP_S05), pedigree-genomic-based models (ssGBLUP_S0) and pedigree-genomic-based incorporating selfing rate in population (ssGBLUP_S05)

1990). These reference values were based on outcrossing rates reported for 10 Eucalyptus species evaluated with isoenzymes loci in seeds or seedlings derived from natural populations (Moran and Bell 1983). In our study, a remarkably low value was obtained $(5.4 \%)$ for a 7 -yearold breeding population of E. globulus growing in exotic conditions. The discrepancy with the reference values can be explained for both environmental and genetic factors. First, in seed orchards and breeding populations the selfing rate may be lower than in natural populations, because all trees are of the same species and age, which favors the synchronization of flowering. Secondly the values of selfing reported by Moran and Bell (1983) were based on studies carried out on seeds or seedlings, while the reports of selfing rates of breeding populations are obtained from trees growing in progeny tests, where many selfings may have dead at early ages due to inbreeding depression. Finally, differences in statistical methods and molecular marker technology may explain the low estimated selfing rate. Recent studies, using multiallelic molecular markers, reported selfing rates between 7.4 and $8.3 \%$ for E. urophylla (Grattapaglia et al. 2004; Pupin et al. 2019) and between 1.8 and $3.2 \%$ for E. camaldulensis (Gonzaga et al. 2016).
Table 4 Percentage of common trees in the top ranked $10 \%$ for different traits between the four models evaluated: ABLUP_S0 (pedigree-based); ABLUP_S05 (pedigree rescaled to selfing rate in the population); ssGBLUP_S0 (combined pedigree marker-based) and ssGBLUP_S05 (combined pedigree marker-based rescaled to selfing rate in the population)

\begin{tabular}{lllll}
\hline Trait_age (months) & $\begin{array}{l}\text { ABLUP_S0 } \\
\text { vs ssGBLUP_S0 }\end{array}$ & $\begin{array}{l}\text { ABLUP_S05 } \\
\text { vs ssGBLUP_S05 }\end{array}$ & $\begin{array}{l}\text { ABLUP_S0 } \\
\text { vs ABLUP_S05 }\end{array}$ & $\begin{array}{l}\text { ssGBLUP_S0 } \\
\text { vs ssGBLUP_S05 }\end{array}$ \\
\hline DEF_21 & 76.3 & 75.0 & 97.9 & 97.3 \\
ADFO_21 & 89.3 & 90.1 & 98.6 & 99.1 \\
HT_26 & 81.5 & 81.8 & 97.3 & 98.8 \\
DBH_50 & 87.0 & 88.0 & 95.3 & 97.6 \\
\hline
\end{tabular}

$D E F$, degree of defoliation; $A D F O$, fraction of adult folage in canopy; $H T$, total tree height; $D B H$, diameter at breast height 
Fig. 3 Predictive abilities of two cross-validation methods: random (CV-random) or between family relatedness (CV-family) for four phenotypic traits and the four models: ABLUP_S0 (pedigree-based); ABLUP_S05 (pedigree rescaled to populational selfing rate); ssGBLUP_S0 (combined pedigree marker-based) and ssGBLUP_S05 (combined pedigree marker-based rescaled to population selfing rate)
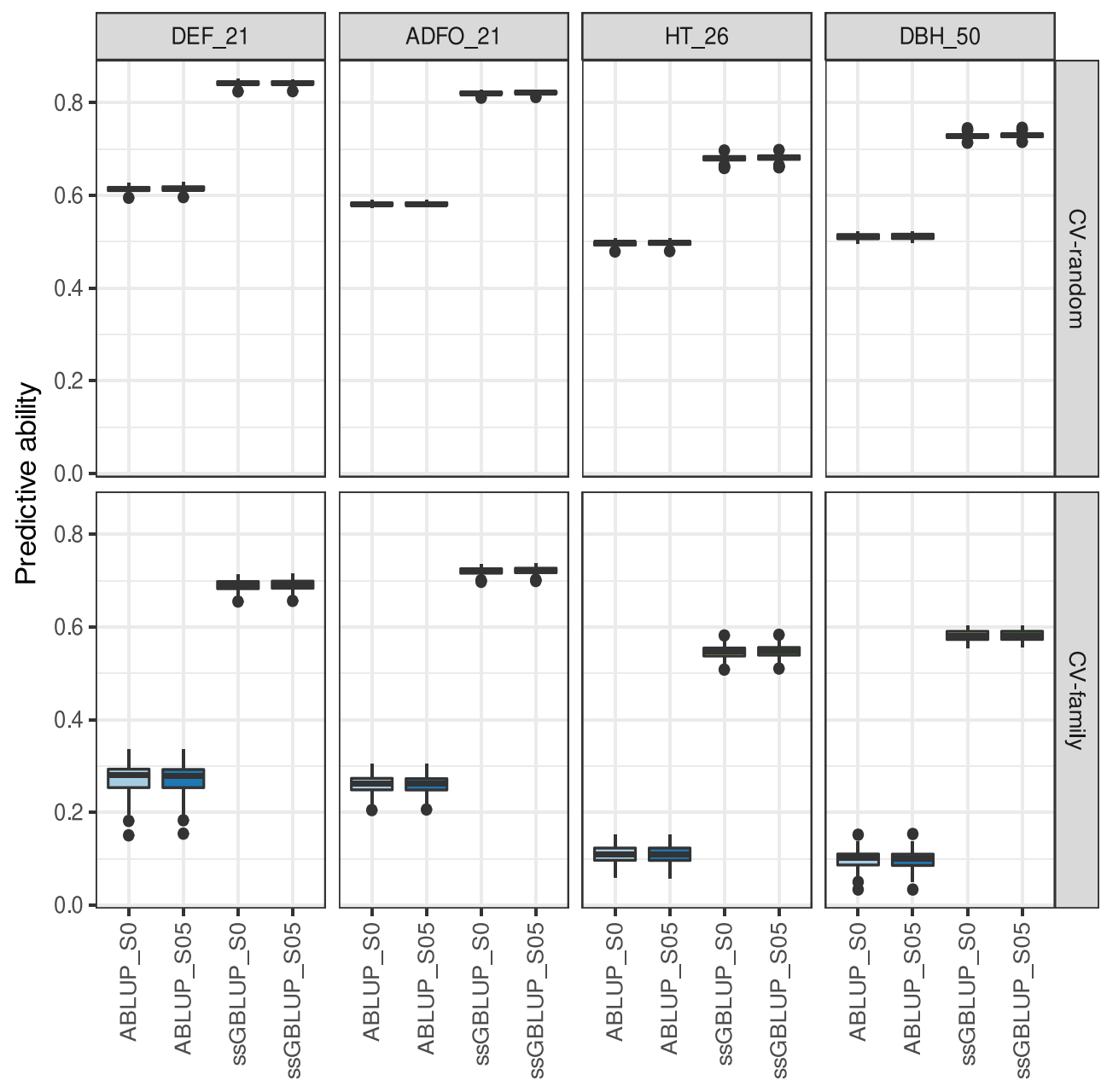

Klápště et al. (2017), using SNP genomic data for pedigree reconstruction and selfing estimation, reported a selfing rate of $4.0 \%$ in E. nitens.

As the selfing rate is specific to a mating event, and can vary among species, populations, and trees and fruits within trees, it is necessary to estimate it from marker data taken from the population under study. However, for tree species is infrequent to genotype a complete population, so it is not possible to identify all self-fertilized individuals. In this study, the populational selfing rate, estimated with a small fraction of the total number of trees, was used as a correction factor for the relationship matrix based on pedigree for the complete population. This correction, with the estimated population selfing rate of $5.4 \%$, resulted in a more reliable relationship information, allowing a more accurate estimation of genetic parameters and breeding values.

\section{Heritability with selfing and genomic information}

It is well known that analyzing open-pollinated progenies as half-sib families without considering selfing results in over-inflated additive genetic variances and heritabilities
(El-Kassaby et al. 2012). The heritabilities estimated in this study decreased between 1.5 and $8.0 \%$ when the selfing rate in the population was incorporated into the pedigree-based model (Table 2). The same pattern was observed by Klápštẽ et al. (2018) when comparing different selfing probabilities. On the other hand, the heritabilities estimated with the marker-based approach were lower than the obtained from pedigree-based models for the diseased related traits and equal or slightly higher for growth traits. The marker-based approach is considered more effective for capturing the full genetic relationships among individuals, including selfing events, resulting in more accurate estimates of the genetic variances (Mphahlele et al. 2020; Müller et al. 2017). This is supported by the improvement of fit (measured through the AIC) obtained with the genomic models.

The discrepancies between rankings obtained with traditional ABLUP and ssGBLUP suggest that including genomic information has an impact on the selection of superior individuals. Other studies in forest trees have demonstrated the increase in the breeding values accuracies by including genomic information, thus increasing the probability of a correct ranking of candidates for selection 
Fig. 4 Bias (regression slope) of two cross-validation methods: random (CV-random) or between family relatedness $(\mathrm{CV}$ family) for the four phenotypic traits and the four models: ABLUP_S0 (pedigree-based); ABLUP_S05 (pedigree rescaled to populational selfing rate); ssGBLUP_S0 (combined pedigree marker-based) and ssGBLUP_S05 (combined pedigree marker-based rescaled to population selfing rate)
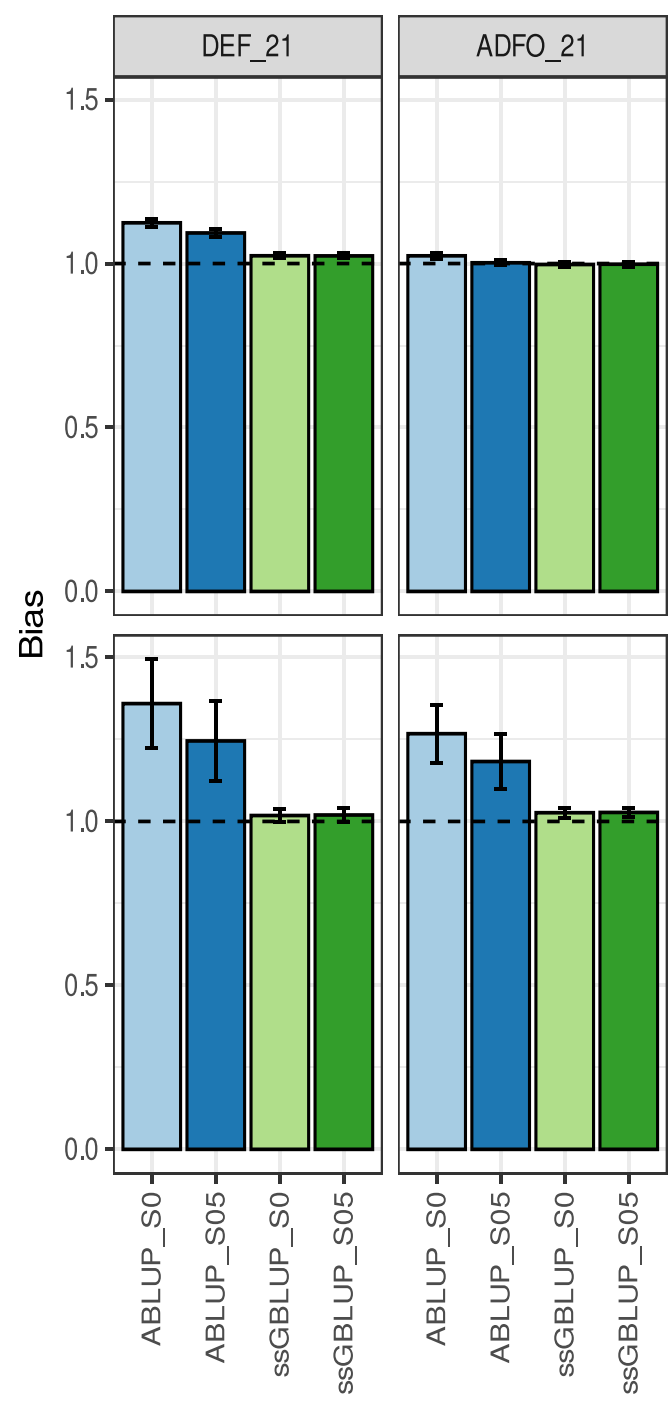

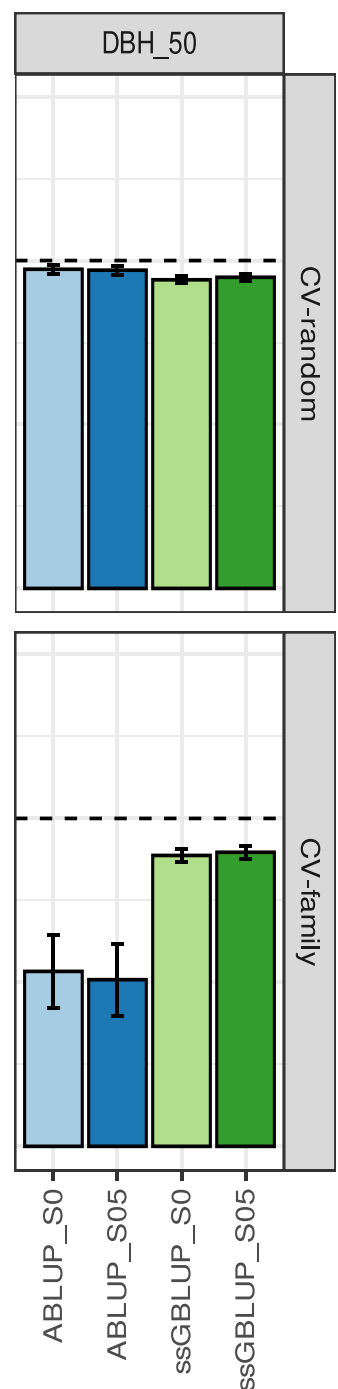

(Cappa et al. 2019; Ratcliffe et al. 2017). In particular, the single-step evaluation, where the genomic relationship between genotyped individuals is projected on nongenotyped individuals, resulted in a more accurate modeling of individual relationships. However, the inclusion of a modified pedigree relationship matrix, accounting for the population selfing rate, did not result in a significant improvement of the breeding values, which is evidenced by minimal changes in the ranking of individuals. Therefore, our results suggest that the inclusion of a genomic relationship matrix in a complete genomic evaluation can efficiently capture the cryptic genetic relationships (including selfing), at least in populations with a low selfing rate.

\section{Performance of the prediction models}

As a benchmark for accuracy assessments of genomic selection, predictive abilities are measured as the correlation between the estimated breeding values and the true breeding values. As the true breeding values are typically unknown, the breeding values estimated using the pedigree information (Cappa et al. 2019), or phenotypic values adjusted by experimental effects, are commonly used as reference values (Resende et al. 2012; Zapata-Valenzuela et al. 2013; Isik et al. 2016). However, we assume that a better estimate of the true breeding values can be achieved by considering all sources of information available, so the breeding values estimated through the simultaneous use of phenotypic, pedigree and genomic information were considered as the standard for comparison. For all traits and cross-validation schemes, the approach that included genomic information outperformed the pedigree-based model, without significant differences with the inclusion of the population selfing rate (Fig. 3). These results are consistent with previous reports on forest tree species that included genomic information using ssGBLUP, GBLUP or Bayesian methods (Ratcliffe et al. 2017; Tan et al. 
Fig. 5 Spearman rank correlation of two crossvalidation methods: random (CV-random) or between family relatedness (CV-family) for four phenotypic traits and the four models: ABLUP_S0 (pedigreebased); ABLUP_S05 (pedigree rescaled to populational selfing rate); ssGBLUP_S0 (combined pedigree marker-based) and ssGBLUP_S05 (combined pedigree marker-based rescaled to population selfing rate)
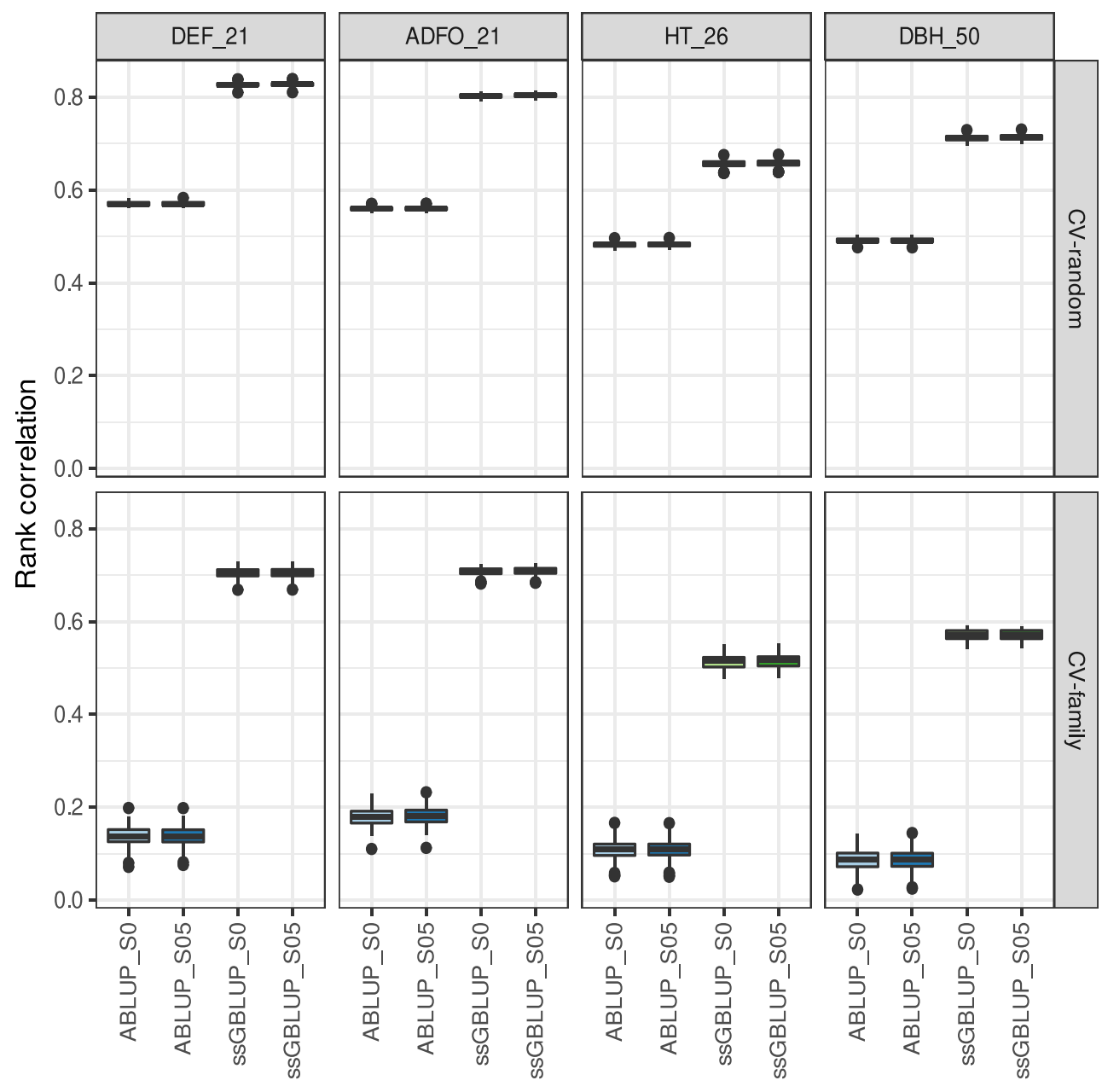

2017). The higher predictive abilities obtaining with the pedigree-genomic-based models may be due to a more precise estimation of genetic relationships captured by markers, i.e., Mendelian segregation. This is specially relevant in breeding populations based on open-pollination, with incomplete pedigree and unknown relationships, where the half-sibs families also include some full-sibs as well as inbreed progeny derived from selfing or mating between close relatives.

The relatively high predictive abilities obtained for traits associated with response to infection by $T$. nubilosa suggest a genetic control under an infinitesimal model, encouraging the application of genomic prediction schemes for these traits in forest tree breeding programs. Lower predictive abilities were obtained for growth traits, but the values are consistent with previous reports in Eucalyptus species. For instance, Ballesta et al. (2018) reported mean predictive abilities of 0.50 and 0.43 for height and DBH in E. globulus; Resende et al. (2012) reported values between 0.46 and 0.55 for the same traits in hybrid populations, and Müller et al. (2017) reported predictive abilities from 0.34 to 0.44 for $E$. pellita. However, accuracy comparisons between different

studies should consider differences in trait heritabilities, markers set, training and validation population sizes and cross-validation methods.

Relatedness between training and validation data sets is another aspect that has a large impact on predictive abilities (Habier et al. 2007). As expected, the predictive abilities for all traits were higher for the CV-random schemes, compared with the CV-family approach where close pedigree relationships between the training and validation data set were intentionally avoided. However, applying the latter approach, low to moderate predictive abilities were obtained with pedigree-based models, suggesting that some historical relatedness persist between families of the training and validation populations. Also, in this openpollinated population, the paternal connections between families are not accounted in the pedigree. When marker information was incorporated, the predictive abilities obtained with the CV-family approach were moderately high, and slightly lower than those obtained with the CV-random approach. Thus, in addition to capturing distant relatedness between families, the predictive abilities obtained with genomic information could also be explained 
by the presence of stable linkage disequilibrium between markers and QTLs across different families. Our results, in line with previous studies in open-pollinated populations of forest tree species, show that markers reveal information about genetic relationships among individuals, as well as historical linkage disequilibrium (Beaulieu et al. 2014). Results are encouraging for breeders relying on openpollinated material, who may question the use of genomic selection in populations with low apparent relationship.

\section{Conclusions}

This research demonstrated that the estimation of pairwise relationships and their comparison with the expected value for parent-offspring relationship is a simple and fast tool to estimate the selfing rate in a forest population. The estimation of the actual selfing rate in the population allows for more reliable estimation of genetic parameters, avoiding the upward bias in additive genetic variance estimates resulting from the use of reference values. Also, the selfing rate can be easily incorporated in a numerator relationship matrix, and this modified matrix can be combined with a genomic relationship matrix to incorporate all the advantages of the genomic selection approach in one procedure. The inclusion of the phenotype of genotyped and non-genotyped trees in a single analysis proved to be effective for the accurate estimation of genetic parameters and to improve the prediction of breeding values. However, the effect of incorporating the population selfing rate in the numerator relationship matrix in a single-step genomic analysis needs to be investigated under higher selfing rates.

Supplementary Information The online version contains supplementary material available at https://doi.org/10.1007/s11295-021-01534-7.

Author contributions GB and IA conceived the study design. GB designed the field experiment, collected the phenotypic data and provided the marker data. MQ carried out the data analysis, under the supervision of IA. MQ wrote the first version of the manuscript. GB and IA edited and revised the manuscript. All authors read and approved the final manuscript.

Funding This work was supported by the Instituto Nacional de Investigación agropecuaria (INIA). MQ received a postdoctoral fellowship from INIA.

Availability of data and material The data sets generated and analyzed during the current study are available from the corresponding author upon reasonable request and with permission of INIA.

\section{Declarations}

Conflict of interest The authors declare no competing interests.

Open Access This article is licensed under a Creative Commons Attribution 4.0 International License, which permits use, sharing, adaptation, distribution and reproduction in any medium or format, as long as you give appropriate credit to the original author(s) and the source, provide a link to the Creative Commons licence, and indicate if changes were made. The images or other third party material in this article are included in the article's Creative Commons licence, unless indicated otherwise in a credit line to the material. If material is not included in the article's Creative Commons licence and your intended use is not permitted by statutory regulation or exceeds the permitted use, you will need to obtain permission directly from the copyright holder. To view a copy of this licence, visit http://creativecommons. org/licenses/by/4.0/.

\section{References}

Aguilar I, Misztal I, Johnson D, Legarra A, Tsuruta S, Lawlor $\mathrm{T}$ (2010) Hot topic: a unified approach to utilize phenotypic, full pedigree, and genomic information for genetic evaluation of Holstein final score. J Dairy Sci 93:743-752. https://doi.org/10.3168/jds.2009-2730

Aguilar I, Misztal I, Legarra A, Tsuruta S (2011) Efficient computation of the genomic relationship matrix and other matrices used in single-step evaluation. J Anim Breed Genet 128:422-428. https://doi.org/10.1111/j.1439-0388.2010.00912.x

Akaike H (1974) A new look at the statistical model identification. IEEE Trans Automat Contr 19:716-723. https://doi.org/10.1109/TAC.1974.1100705

Ballesta P, Serra N, Guerra FP, Hasbún R, Mora F (2018) Genomic prediction of growth and stem quality traits in Eucalyptus globulus Labill at its southernmost distribution limit in Chile. Forests 9:1-18. https://doi.org/10.3390/f9120779

Balmelli G, Simeto S, Torres D, Castillo A, Altier N, Diez JJ (2013) Susceptibility to Teratosphaeria nubilosa and precocity of vegetative phase change in Eucalyptus globulus and E. maidenii (Myrtaceae). Aust J Bot 61:583-591. https://doi.org/10.1071/BT13225

Balmelli G, Simeto S, Torres D, Hirigoyen A, Castillo A, Altier N, Pérez G, Diez JJ (2016) Impact of Teratosphaeria nubilosa over tree growth and survival of Eucalyptus globulus and Eucalyptus maidenii in Uruguay. New For 47:829-843. https://doi.org/10.1007/s11056-016-9547-3

Beaulieu J, Doerksen T, Clément S, Mackay J, Bousquet J (2014) Accuracy of genomic selection models in a large population of open-pollinated families in white spruce. Heredity 113:343-352. https://doi.org/10.1038/hdy.2014.36

Bush D, Kain D, Matheson C, Kanowski P (2011) Markerbased adjustment of the additive relationship matrix for estimation of genetic parameters-an example using Eucalyptus cladocalyx. Tree Genet Genomes 7:23-35. https://doi.org/10.1007/s11295-010-0312-z

Butler DG, Cullis BR, Gilmour AR, Gogel BJ, Thompson R (2018) ASReml-R reference manual version 4. http://www.homepages. ed.ac.uk/iwhite/asreml/uop

Cappa EP, Klápště J, Garcia MN, Villalba PV, Marcucci Poltri SN (2016) SSRS, SNPs and DArts comparison on estimation of relatedness and genetic parameters' precision from a small halfsib sample population of Eucalyptus grandis. Mol Breed 36:97. https://doi.org/10.1007/s11032-016-0522-7

Cappa EP, de Lima BM, da Silva-Junior OB, Garcia CC, Mansfield SD, Grattapaglia D (2019) Improving genomic prediction of growth and wood traits in Eucalyptus using phenotypes from non-genotyped trees by single-step GBLUP. Plant Sci 284:9-15. https://doi.org/10.1016/j.plantsci.2019.03.017

Christensen OF (2012) Compatibility of pedigree-based and markerbased relationship matrices for single-step genetic evaluation. Genet Sel Evol 44. https://doi.org/10.1186/1297-9686-44-37 
Christensen OF, Lund MS (2010) Genomic prediction when some animals are not genotyped. Genet Sel Evol 42. https://doi.org/10.1186/1297-9686-42-2

Dutkowski GW, Gilmour AR, Borralho NMG (2001) Modification of the addditive relationship matrix for open pollinates trials. In: Barros R, Ipinzà E (eds) Developing the eucalypt of the future. Proceedings of the IUFRO, Valdivia, $\mathrm{p} 10$

El-Kassaby YA, Klápště J, Guy RD (2012) Breeding without breeding: selection using the genomic best linear unbiased predictor method (GBLUP). New For 43:631-637. https://doi.org/10.1007/s11056-012-9338-4

Eldridge K, Davidson J, Harwood CE, van Wyk G (1993) Eucalypt domestication and breeding. Clarendon, Oxford

Forni S, Aguilar I, Misztal I (2011) Different genomic relationship matrices for single-step analysis using phenotypic, pedigree and genomic information. Genet Sel Evol 43. https://doi.org/10.1186/1297-9686-43-1

Gonzaga JM, Manoel RO, Sousa AC, Souza AP, Moraes ML, Freitas ML, Sebbenn AM (2016) Pollen contamination and nonrandom mating in a Eucalyptus camaldulensis Dehnh seedling seed orchard. Silvae Genet 65:1-11. https://doi.org/10.1515/sg-2016-0001

Grattapaglia D, Ribeiro VJ, Rezende GD (2004) Retrospective selection of elite parent trees using paternity testing with microsatellite markers: an alternative short term breeding tactic for Eucalyptus. Theor Appl Genet 109:192-199. https://doi.org/10.1007/s00122-004-1617-9

Griffin A, Cotterill P (1988) Genetic variation in growth of outcrossed, selfed and open-pollinated progenies of Eucalyptus regnans and some implications for breeding strategy. Silvae Genet 37(3):124131

Habier D, Fernando RL, Dekkers JCM (2007) The impact of genetic relationship information on genomeassisted breeding values. Genetics 177(4):2389-2397. https://doi.org/10.1534/genetics.107.081190

Isik F, Bartholomé J, Farjat A, Chancerel E, Raffin A, Sanchez L, Plomion C, Bouffier L (2016) Genomic selection in maritime pine. Plant Sci 242:108-119. https://doi.org/10.1016/j.plantsci.2015.08.006

Isik F, Holland J, Maltecca C (2017) Genetic data analysis for plant and animal breeding. Springer International Publishing, Cham. https://doi.org/10.1007/978-3-319-55177-7_1

Kalinowski ST, Taper ML, Marshall TC (2007) Revising how the computer program CERVUS accommodates genotyping error increases success in paternity assignment. Mol Ecol 16:10991106. https://doi.org/10.1111/j.1365-294X.2007.03089.x

Klápště J, Suontama M, Telfer E, Graham N, Low C, Stovold T, McKinley R, Dungey H (2017) Exploration of genetic architecture through sib-ship reconstruction in advanced breeding population of Eucalyptus nitens. PLoS ONE 12:e0185137. https://doi.org/10.1371/journal.pone.0185137

Klápštẽ J, Suontama M, Dungey HS, Telfer EJ, Graham NJ, Low CB, Stovold GT (2018) Effect of hidden relatedness on Single-Step genetic evaluation in an advanced Open-Pollinated breeding program. J Hered 109:802-810. https://doi.org/10.1093/jhered/esy051

Kopps AM, Kang J, Sherwin WB, Palsbøll PJ (2015) How well do molecular and pedigree relatedness correspond, in populations with diverse mating systems, and various types and quantities of molecular and demographic data? G3 Genes Genomes Genet 5:1815-1826. https://doi.org/10.1534/g3.115.019323

Legarra A, Aguilar I, Misztal I (2009) A relationship matrix including full pedigree and genomic information. J Dairy Sci 92:4656-4663. https://doi.org/10.3168/jds.2009-2061
Marroni F, Pinosio S, Zaina G, Fogolari F, Felice N, Cattonaro F, Morgante M (2011) Nucleotide diversity and linkage disequilibrium in Populus nigra cinnamyl alcohol dehydrogenase (CAD4) gene. Tree Genet Genomes 7(5):1011-1023. https://doi.org/10.1007/s11295-011-0391-5

Masuda Y, Legarra A, Aguilar I, Misztal I (2019) 311 Efficient quality control methods for genomic and pedigree data used in routine genomic evaluation. J Anim Sci 97:50-51. https://doi.org/10.1093/jas/skz258.101

Meuwissen THE, Hayes BJ, Goddard ME (2001) Prediction of total genetic value using genome-wide dense marker maps. Genetics 157:1819-1829

Milgate AW, Potts BM, Joyce K, Mohammed C, Vaillancourt RE (2005) Genetic variation in Eucalyptus globulus for susceptibility to Mycosphaerella nubilosa and its association with tree growth. Australas Plant Pathol 34:11-18. https://doi.org/10.1071/AP04073

Milligan BG (2003) Maximum-likelihood estimation of relatedness. Genetics 163:1153-1167

Misztal I, Tsuruta S, Strabel T, Auvray B, Druet T, Lee DH (2002) blupf90 and related programs (BGF90). In: 7th World congress on genetics applied to livestock production, Montpellier, $\mathrm{p} 21$

Misztal I, Aggrey SE, Muir WM (2013) Experiences with a single-step genome evaluation. Poult Sci 92:2530-2534. https://doi.org/10.3382/ps.2012-02739

Moran GF, Bell JC (1983) Eucalyptus. In: Tanksley SD, Orton TJ (eds) Isozymes plant genet breed, vol Part B. Elsevier, pp 423-441. https://doi.org/10.1016/B978-0-444-42227-9.50024-X

Mphahlele MM, Isik F, Mostert-O'Neill MM, Reynolds SM, Hodge GR, Myburg AA (2020) Expected benefits of genomic selection for growth and wood quality traits in Eucalyptus grandis. Tree Genet Genomes 16:12. https://doi.org/10.1007/s11295-020-01443-1

Mrode R (2014) Linear models for the prediction of animal breeding values. $\mathrm{CABI}$

Müller BS, Neves LG, de Almeida Filho JE, Resende MF, Muñoz PR, dos Santos PE, Filho EP, Kirst M, Grattapaglia D (2017) Genomic prediction in contrast to a genome-wide association study in explaining heritable variation of complex growth traits in breeding populations of Eucalyptus. BMC Genomics 18. https://doi.org/10.1186/s12864-017-3920-2

Muñoz PR, Resende MF, Huber DA, Quesada T, Resende MD, Neale DB, Wegrzyn JL, Kirst M, Peter GF (2014) Genomic relationship matrix for correcting pedigree errors in breeding populations: impact on genetic parameters and genomic selection accuracy. Crop Sci 54:1115-1123. https://doi.org/10.2135/cropsci2012.12.0673

Namkoong G (1965) Inbbreeding effects on estimation of genetic additive variance. For Sci 12(1891):8-13

Patterson B, Vaillancourt RE, Pilbeam DJ, Potts BM (2004) Factors affecting variation in outcrossing rate in Eucalyptus globulus. Aust J Bot 52:773-780. https://doi.org/10.1071/BT03186

Pew J, Muir PH, Wang J, Frasier TR (2015) Related: an R package for analysing pairwise relatedness from codominant molecular markers. Mol Ecol Resour 15:557-561. https://doi.org/10.1111/1755-0998.12323

Pupin S, Sebbenn AM, Cambuim J, da Silva AM, Zaruma DU, Silva PH, Rosse LN, Souza IC, Marino CL, Moraes ML (2019) Effects of pollen contamination and non-random mating on inbreeding and outbreeding depression in a seedling seed orchard of Eucalyptus urophylla. For Ecol Manage 437:272-281. https://doi.org/10.1016/j.foreco.2019.01.050

R Core Team (2018) R: a language and environment for statistical computing. https://www.r-project.org/ 
Ratcliffe B, El-Dien OG, Cappa EP, Porth I, Klápště J, Chen C, ElKassaby YA (2017) Single-step BLUP with varying genotyping effort in open-pollinated Picea glauca. G3 Genes Genomes Genet 7:935-942. https://doi.org/10.1534/g3.116.037895

Resende MD, Resende MF, Sansaloni CP, Petroli CD, Missiaggia AA, Aguiar AM, Abad JM, Takahashi EK, Rosado AM, Faria DA, Pappas GJ, Kilian A, Grattapaglia D (2012) Genomic selection for growth and wood quality in Eucalyptus: capturing the missing heritability and accelerating breeding for complex traits in forest trees. New Phytol 194:116-128. https://doi.org/10.1111/j.1469-8137.2011.04038.x

Silva-Junior OB, Faria DA, Grattapaglia D (2015) A flexible multispecies genome-wide 60K SNP chip developed from pooled resequencing of 240 Eucalyptus tree genomes across 12 species. New Phytol 206:1527-1540. https://doi.org/10.1111/nph.13322

Squillace AE (1974) Average genetic correlations among offspring from open-pollinated forest trees. Silvae Genet 23:149-156

Tambarussi EV, Pereira FB, da Silva PHM, Lee D, Bush D (2018) Are tree breeders properly predicting genetic gain? A case study involving Corymbia species. Euphytica 214:150. https://doi.org/10.1007/s10681-018-2229-9

Tan B, Grattapaglia D, Martins GS, Ferreira KZ, Sundberg B, Ingvarsson PK (2017) Evaluating the accuracy of genomic prediction of growth and wood traits in two Eucalyptus species and their F1 hybrids. BMC Plant Biol 17. https://doi.org/10.1186/s12870-017-1059-6

Ukrainetz NK, Mansfield SD (2020) Assessing the sensitivities of genomic selection for growth and wood quality traits in lodgepole pine using Bayesian models. Tree Genet Genomes 16:14. https://doi.org/10.1007/s11295-019-1404-z

VanRaden PM (2008) Efficient methods to compute genomic predictions. J Dairy Sci 91:4414-4423. https://doi.org/10.3168/jds.2008-1929
Visscher PM, Medland SE, Ferreira MA, Morley KI, Zhu G, Cornes BK, Montgomery GW, Martin NG (2006) Assumptionfree estimation of heritability from genome-wide identity-bydescent sharing between full siblings. PLoS Genet 2:e41. https://doi.org/10.1371/journal.pgen.0020041

Vitezica ZG, Aguilar I, Misztal I, Legarra A (2011) Bias in genomic predictions for populations under selection. Genet Res 93:357366. https://doi.org/10.1017/S001667231100022X

Volker P, Dean C, Tibbits W (1990) Genetic parameters and gains expected from selection in Eucalyptus globulus in Tasmania. Silvae Genet 39:18-21

Wang J (2007) Triadic IBD coefficients and applications to estimating pairwise relatedness. Genet Res 89:135-153. https://doi.org/10.1017/S0016672307008798

Wang J (2011) Coancestry: a program for simulating, estimating and analysing relatedness and inbreeding coefficients. Mol Ecol Resour 11:141-145. https://doi.org/10.1111/j.1755-0998.2010.02885.x

Wang J, El-Kassaby YA, Ritland K (2012) Estimating selfing rates from reconstructed pedigrees using multilocus genotype data. Mol Ecol 21:100-116. https://doi.org/10.1111/j.1365-294X.2011.05373.x

Zapata-Valenzuela J, Whetten RW, Neale D, Mckeand S, Isik F (2013) Genomic estimated breeding values using genomic relationship matrices in a cloned population of loblolly pine. g3 genes, genomes. Genet 3:909-916. https://doi.org/10.1534/g3.113.005975

Publisher's note Springer Nature remains neutral with regard to jurisdictional claims in published maps and institutional affiliations. 